\title{
除塵機導入による調剤室内糜埃数の变化*1
}

\author{
林 弘鿆, 秋田昌宏, 近藤源作, 須原清治 \\ 名古屋大学医学部付属病院薬剂部*2
}

\section{Reduction in Number of Dust Particles by Vacuum Cleaner*1}

\author{
Hirosuke Hayashi, MASAhiro AKita, GenSAKU \\ KONDO, and KIYOHARU SUHARA \\ Pharmacy, Nagoya University Hospital*2
}

(Received February 15, 1980)

\begin{abstract}
Dust particles in hospital pharmacy were reduced to $1 / 10$ to $1 / 50$ by an electric vacuum cleaner placed near the source of dust. The dust removal rate in the area away from the cleaner was lower : $1 / 3$ to $1 / 15$. Dust particles produced in drug dispensing consisted of relatively large ones (1. $0-5.0 \mu \mathrm{m}$ in diameter), and most of those due to other factors such as smoking and working personnel were smaller $(0.3-0.5 \mu \mathrm{m})$. Consequently, the ratio of large dust particles of $1.0-5.0 \mu \mathrm{m}$ was higher in pharmacy than in other places, and the ratio of small ones of $0.3-0.5 \mu \mathrm{m}$ was not so higher. When the vacuum cleaner was placed near the source of dust, most of the large particles over $1.0-5.0 \mu \mathrm{m}$ were removed. Consequently, the particles of this size were reduced in any part of pharmacy. However, smaller particles of $0.3-0.5 \mu \mathrm{m}$ were not efficiently removed in the area distant from the cleaner: particles left unremoved in such area were 3 to 6 folds as many as in the place around the cleaner.
\end{abstract}

病院薬局調剂室における環境衛生については, 各病院 においてその規模によりそれぞれの方策によって改善に 努力している．これら環境衛生のうち最近とくに問題と なっている薬鹿によるフレルギーについてす多く報告さ れ1-4)，その対策も種々試みられている(5,6)。またこれら 薬鹿によるアレルギーの防止についても，1974年に全 国病院薬剂部長会で「調剤室内薬塵の実態调査」がなさ $れ^{7)}, 1978$ 年には日本病院薬㶡師会の薬剂業務検討特別 委員会においてもその最初の仕事として「薬局における 薬蝔の実態調査」が実施された8)。われわれる调剤室の 薬塵防止法としてメリックスフード MR-5000（分包機 用), MR-5100 (調剂台用) 東京商会製を設置し, 環境 衛生の改善と薬剤部職員の健康管理対策を講じ, その刘

*1 本報を病院薬局の環境衛生改善に関す万研究(第 1 報）とする.日本薬学会第99年会（札幌, 1979年 8 月）で発表.

*2 名古屋市 昭和区 鶴舞町 $65 ; 65$, Tsurumai-cho, Showa-ku, Nagoya, 466 Japan
果について検信し，若干の知見を得たので報告する。

\section{実 験 の 部}

\section{実験方法}

木院は調剤室を外来と入院にわけ外来調剂室は 1 階, 入院㓮剂室は地階にあり, 本研究は外来調剤室を対象と して行った. 外来調剂室は全部で約 $154 \mathrm{~m}^{2}$, そのうち約 2/3を调剂室残りを调剂隼備室と区分している。外来調剤 処方せん枚数は 1 日約 700 枚, 薬剤師 12 名, 薬剤補助員 5 名, 研修生若干名であり, 散剤の混合は乳錸, 乳棒 を, 分包は東和式自動調剂分包機 VS-42型 1 台, VS-28 型 1 台を使用している。调剤室の薬塵発生源は主に散剂 调剂台, 分包機の周辺であり, これにメリックス MR5000 (風量0 $29 \mathrm{~m}^{3} / \mathrm{min}$ ), $\mathrm{MR}-5100$ (風量0 $96 \mathrm{~m}^{3} / \mathrm{min}$ ) を設置し, 网1 亿示したように薬麇発生源近くのA点, 调剂室と调剂隼備宾の境 $\mathrm{B}$ 点に打いて, 除蝔機'の 稼動 時, 停川時の蝔埃を時間を追って光散乱式パーチクルカ ウンターKC-01型（リオン製）にて歴埃量を0.3，0.5, 
$1.0 ， 2.0 ， 5.0 \mu$ 以上にわけてその数を測定した．各蚍埃 量は 5 回測定, 万ち 3 回の平均值を求めた.

測定は環境温度 $25 \sim 28^{\circ}$, 混度 RH 65 70\%において 行った.
実跧結果と考樌

\section{調剂室と他室の哯埃量}

木研究を行らにあたり調剂室とその他の部署との塵埃
A. 测定焏 $\mathrm{A}$
B. 測分点 B
C. 散詴詰替室
1. 処方せん受付
2. 書記机
3. 錠绪調詴台
4. 散剂調削台
5. 水刘調剂台
6. 外用剂調绪台
7. 分包機
8. 監查台
9. 投菜瓶佣
10. ペルトコンペア
11. 薬棛渡し口
12. 投菜棚
13. 番号表示用与上操作器
14. 投菜用番号表示器
15. 垥藏㢆
16. リフト
17. スタックランナー
18. 処方世ん収納康
19. タスターシュート
20. 流 L
21. スクリーン付黑板
22. 除塺機
23. 空調機
D. 机
L . 保管庽
P. 获袋・分包紙棚
R. 薬品椆
T. 台

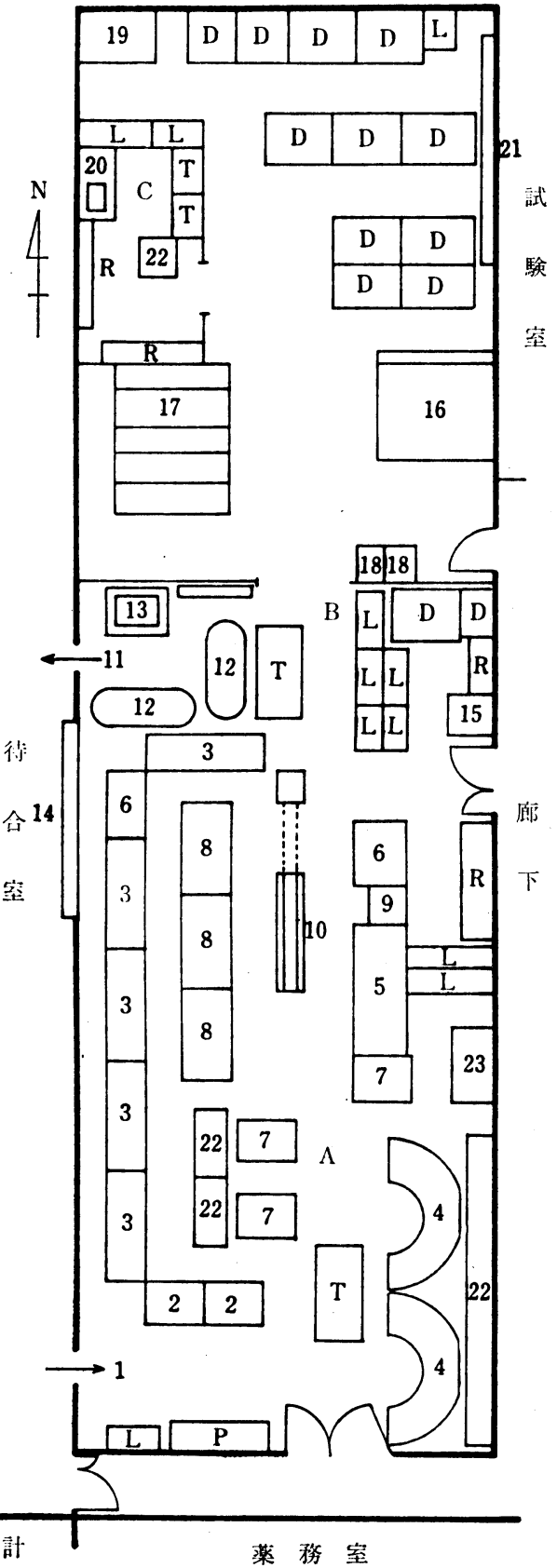

図 1 . 外来調剈室見取図 (1: 154) 
量を求めた. 薬剤部のらち比較的人の出入り, 薬摩の発 た。 生の少ない試験空と啁剂窒の塵垁量を測定し表 1 亿示し

表 1. 調剂室と他室の塵埃量

\begin{tabular}{|c|c|c|c|c|c|c|c|c|}
\hline & & & & 0.3 & 0.5 & 1 & 2 & $5 \mu$ \\
\hline \multirow{2}{*}{ A.M. 10} & 蛙 & 涘 & 室 & 8766 & 707 & 16 & 2 & 0 \\
\hline & 铜 & 玮 & 室 & 8656 & 753 & 129 & 88 & 38 \\
\hline \multirow{2}{*}{ P.M. 1} & 彭 & 埌 & 室 & 3912 & 177 & 21 & 9 & 2 \\
\hline & 铜 & 玮 & 室 & 7797 & 678 & 187 & 106 & 33 \\
\hline \multirow{2}{*}{ P.M. 3} & tot & 娭 & 室 & 5033 & 273 & 25 & 9 & 3 \\
\hline & 调 & 剂 & 室 & 5429 & 459 & 123 & 67 & 20 \\
\hline
\end{tabular}

表1を見ると分かるように，13㭙以外は $03 \sim 05 \mu$ の 粒径の小さい塵埃は倵験室と调剂室てほ注同じてある

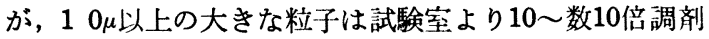
室の方が多く，これが周剤により発生した薬蝔によるも のと考学られる. 粒径 $03 \sim 0.5 \mu$ の塵埃は人の動き, 契 煙などにより影響し，試験室の13時にこの塵埃が少ない
のは传事等により人がいなくなるためと考える

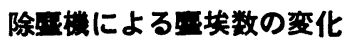

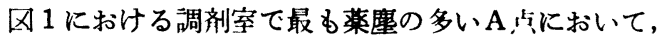

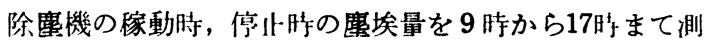
定し衣2 に示した。

表 2 除塺機による塵埃数の変化

$\left(\times 10^{3}\right)$

\begin{tabular}{|c|c|c|c|c|c|c|c|c|c|c|c|}
\hline 粓子 径 & 除しん機 & 9 & 10 & 11 & 12 & 13 & 14 & 15 & 16 & 17（時） & $M \pm S D$ \\
\hline \multirow{2}{*}{$0.3 \mu$} & 無 & 6840 & 8656 & 8482 & 9377 & 7797 & 6528 & 5429 & 5209 & 5928 & \multirow{2}{*}{$\begin{array}{l}7138.3 \pm 1419.2 \\
8306.7 \pm 2519.3\end{array}$} \\
\hline & 有 & 13961 & 899 & 781 & 656 & 661 & 1549 & 911 & 1196 & 581 & \\
\hline \multirow{2}{*}{$0.5 \mu$} & 無 & 662 & 753 & 807 & 1044 & 678 & 465 & 459 & 258 & 300 & \multirow{2}{*}{$\begin{array}{l}602.9 \pm 240.0 \\
691.6 \pm 369.0\end{array}$} \\
\hline & 有 & 1376 & 43 & 35 & 33 & 31 & 61 & 43 & 41 & 24 & \\
\hline \multirow{2}{*}{$1.0 \mu$} & 無 & 71 & 129 & 251 & 339 & 187 & 124 & 123 & 16 & 23 & \multirow{2}{*}{$\begin{aligned} 140.4 & \pm 99.1 \\
73.7 & \pm 43.7\end{aligned}$} \\
\hline & 有 & 27 & 7 & 7 & 7 & 8 & 8 & 13 & 5 & 2 & \\
\hline \multirow{2}{*}{$2.0 \mu$} & 無 & 40 & 88 & 155 & 197 & 106 & 73 & 67 & 5 & 10 & \multirow{2}{*}{$\begin{array}{l}82.3 \pm 60.0 \\
35.6 \pm 23.6\end{array}$} \\
\hline & 有 & 4 & 3 & 3 & 3 & 5 & 5 & 9 & 2 & 0 & \\
\hline \multirow{2}{*}{$5.0 \mu$} & 無 & 20 & 38 & 49 & 57 & 33 & 22 & 20 & 2 & 2 & \multirow{2}{*}{$\begin{array}{c}27.3 \pm 18.0 \\
9.2 \pm 5.7\end{array}$} \\
\hline & 有 & 0 & 0 & 0 & 0 & 1 & 0 & 5 & 0 & 0 & \\
\hline
\end{tabular}

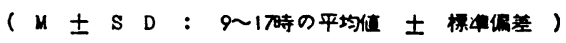

表 2 は, 9 時に啁㶡開始と同時に糜埃数を測定し, 同 時に除塵機を稼動した. 除蚍機停止時は $0.3 \mu$ 以下の粒佳 の小さい塺埃は一日中 $5000 \times 10^{3}$ 倜以上あり, 各粒径と
も12時前後が最も多く, 外来调剂業務の終了15時には少 なくなった．とくに $20 \sim 5.0 \mu$ 以上の粒径の大きい塵埃 は業務のピーク時と比べて调放終了によって $1 / 20 \sim 1 / 30$ 
と隇少した。しかし除摩機を稼動したときは時間による 差はあまりなかった．除摩機の稼動時，停止時の間には 大きい粒径の場合10〜15倍, 小さい粒径の場合20３5倍 と蝔埃量に大きな差があった. 表 2 の平均値と標㔼偏差 (S. D.) は除框機稼動後すなわち 10〜17 時の平均値と 標準偏美である. 表 $4 \sim 6$ も同様で, 表 3 の除蝔機停止
時は 9 〜 17時の平均値を求めた。

\section{场所による䣦埃数の変化}

除蝔機の調剂台用 MR-5100，分包機用MR-5000 を同 時に稼動，停止およひそのどちらか一方のみ稼動したと きの麾埃量を図 1 のA点, B 点で測定し，場所による影 響について検討し表 $3 \sim 6$ 亿示した。

3. 場芹による塺埃数の変化 除摩機停止

\begin{tabular}{|c|c|c|c|c|c|c|c|c|c|c|c|}
\hline 杠子径 & 场 所 & 9 & 10 & 11 & 12 & 13 & 14 & 15 & 16 & 17 (時) & $M \pm S D$ \\
\hline \multirow{2}{*}{$0.3 \mu$} & A & 6840 & 8656 & 8482 & 9377 & 7797 & 6528 & 5429 & 5209 & 5927 & \multirow{2}{*}{$\begin{aligned} 7175.8 & \pm 1501.0 \\
904.3 & \pm 304.4\end{aligned}$} \\
\hline & B & 6867 & 7805 & 7707 & 10423 & 11195 & 13062 & 5728 & 5096 & 6877 & \\
\hline \multirow{2}{*}{$0.5 \mu$} & $\boldsymbol{A}$ & 662 & 753 & 807 & 1044 & 678 & 465 & 459 & 258 & 300 & \multirow{2}{*}{$\begin{array}{c}595.5 \pm 253.6 \\
38.9 \pm 10.4\end{array}$} \\
\hline & B & 643 & 565 & 612 & 980 & 862 & 1535 & 400 & 256 & 371 & \\
\hline \multirow{2}{*}{$1.0 \mu$} & $\mathbf{A}$ & 71 & 129 & 251 & 339 & 187 & 124 & 123 & 16 & 24 & \multirow{2}{*}{$\begin{array}{c}149.0 \pm 102.0 \\
7.1 \pm 2.9\end{array}$} \\
\hline & B & 35 & 48 & 107 & 119 & 105 & 145 & 63 & 16 & 25 & \\
\hline \multirow{2}{*}{$2.0 \mu$} & A & 40 & 88 & 155 & 197 & 106 & 73 & 67 & 5 & 10 & \multirow{2}{*}{$\begin{array}{c}87.6 \pm 61.6 \\
3.8 \pm 2.5\end{array}$} \\
\hline & B & 12 & 24 & 60 & 62 & 48 & 71 & 28 & 6 & 9 & \\
\hline \multirow{2}{*}{$5.0 \mu$} & $\boldsymbol{A}$ & 20 & 40 & 49 & 57 & 33 & 22 & 20 & 2 & 3 & \multirow{2}{*}{$\begin{array}{c}27.9 \pm 18.9 \\
0.8 \pm 1.6\end{array}$} \\
\hline & B & 5 & 7 & 18 & 14 & 10 & 17 & 8 & 2 & 2 & \\
\hline
\end{tabular}

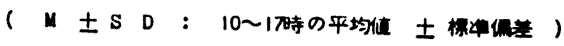

表 4. 場所による塺埃数の変化 除塺機稼動

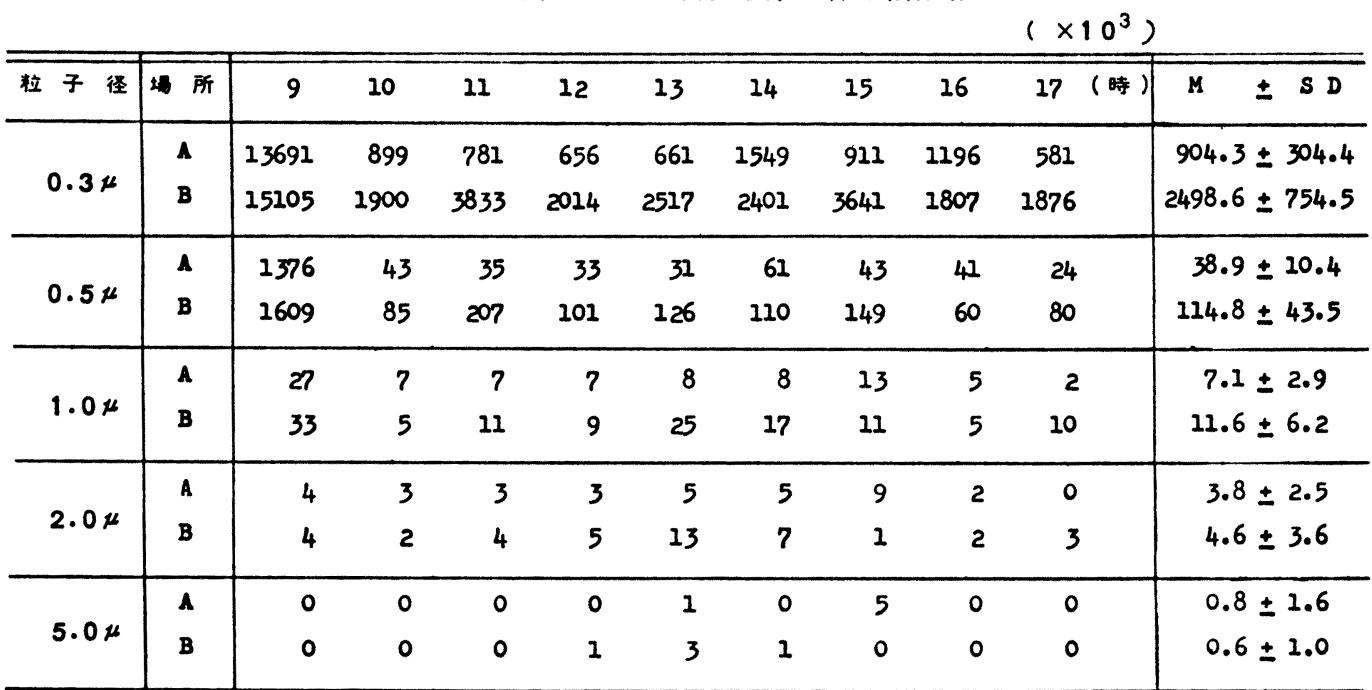


表 5. 場所に上る麾埃数の変化 分包機用除框機稼動

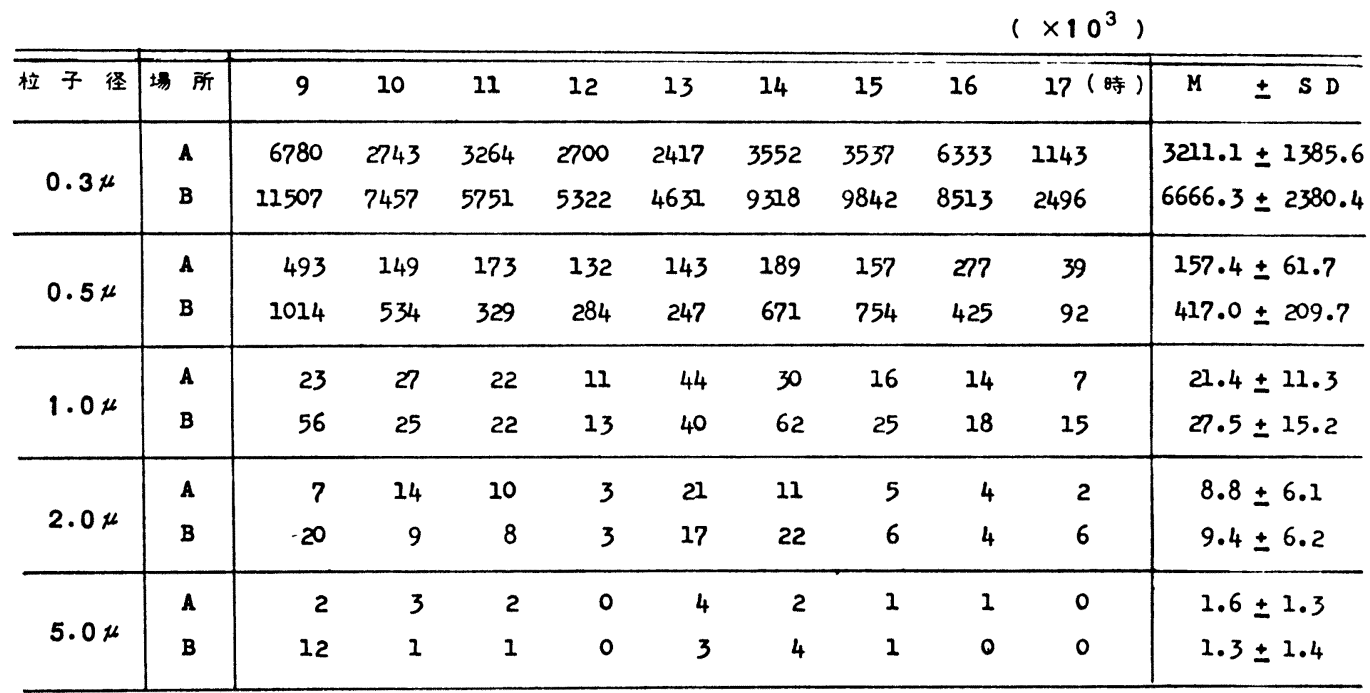

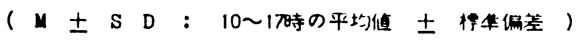

表 6. 場所による塵埃数の変化 調剤台用除應機稼動

$$
\left(\times 10^{3}\right)
$$

\begin{tabular}{|c|c|c|c|c|c|c|c|c|c|c|c|}
\hline 林子 径 & 場 所 & 9 & 10 & 11 & 12 & 13 & 14 & 15 & 16 & 17 (時) & $M \pm S D$ \\
\hline \multirow{2}{*}{$0.3 \mu$} & A & 12250 & 3541 & 4430 & 2272 & 2407 & 2246 & 1690 & 3206 & 1267 & \multirow{2}{*}{$\begin{array}{l}2632.4 \pm 966.2 \\
5587.6 \pm 1290.6\end{array}$} \\
\hline & B & 7130 & 5189 & 7056 & 5650 & 3352 & 4654 & 5902 & 7782 & 5116 & \\
\hline \multirow{2}{*}{$0.5 \mu$} & $\mathbf{A}$ & 1192 & 209 & 338 & 104 & 107 & 107 & 74 & 124 & 63 & \multirow{2}{*}{$\begin{array}{l}140.8 \pm 85.1 \\
341.3 \pm 117.1\end{array}$} \\
\hline & B & 424 & 316 & 572 & 312 & 156 & 275 & 285 & 454 & 360 & \\
\hline \multirow{2}{*}{$1.0 \mu$} & A & 26 & 18 & 33 & 12 & 23 & 12 & 18 & 8 & 4 & \multirow{2}{*}{$\begin{array}{l}16.0 \pm 8.6 \\
20.4 \pm 4.3\end{array}$} \\
\hline & B & 29 & 16 & 27 & 17. & 19 & 28 & 19 & 20 & 17 & \\
\hline \multirow{2}{*}{$2.0 \mu$} & A & 4 & 8 & 15 & 5 & 11 & 4 & 10 & 3 & 0 & \multirow{2}{*}{$\begin{array}{l}7.0 \pm 4.6 \\
5.9 \pm 1.7\end{array}$} \\
\hline & B & 10 & 4 & 6 & 6 & 6 & 9 & 7 & 6 & 3 & \\
\hline \multirow{2}{*}{$5.0 \mu$} & A & 0 & 2 & 4 & 1 & 2 & 0 & 3 & 0 & 0 & \multirow{2}{*}{$\begin{array}{l}1.5 \pm 1.4 \\
1.1 \pm 0.6\end{array}$} \\
\hline & B & 1 & 1 & 1 & 1 & 1 & 2 & 2 & 1 & 0 & \\
\hline
\end{tabular}

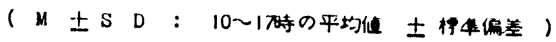

表 3 は除麇機を全部停止したときの蝔埃数で, 薬鹿発 生源に近いA点では 0.3 0.5 $\mu$ の小さい粒径のものは B 点とほぼ同じかやや少なくなっているが, 1. 0 〜 $5.0 \mu$ の 粒径の大きいものはB点よりはるかに多い.

表 4 は除鹿機 MR-5100 (調剤台用)，MR-5000 (分包 機用）とも稼動しているときで, A点では表 3 に比し
$0.3 \sim 0.5 \mu$ のものは $1 / 10 \sim 1 / 15$ に减少するが, B 点では 1/3〜1/6 と少なくなった。表 4 のA点と B点の間には $0.3 \sim 0.5 \mu$ の小さい粒径ては約 3 倍 $\mathrm{B}$ 点が多く, 1. 0 $5.0 \mu$ の塵埃数はA点とB点との間にあまり大きな差はな くなり, 表 3 と逆の結果となったここことは調剤, 分 包により発生した $1.0 \sim 5.0 \mu$ の薬鹿は除塵機が稼動しな 
いときは一部B点近くまで飛散するが，除歴機の稼動に より $\mathrm{A}$ 点において除去され，B点まで飛散しない，この ため $10 \sim 50 \mu$ の蝔埃量はA 点と B 只とほぼ同じとなる が，表 1 の他室との比較の場合と闪㥞に，调剂によらな い他の要因に上り発生する $03 \sim 05 \mu$ の蝔埃は除蝔機の 効果が $\mathrm{B}$ 点まではあまり大きく影掣せず，B， るかに多くなったと考える。

表 5は MR-5000，表6は MR-5100のどちらかのみ稀 動した場合て，A点における鹿埃は両力稼動した場合に 比して当然多くなった。

表 5 と表 6 を比較すると，处 5 の分公機用の际鹿㙨椽 動時の方が表 6 の、周剂台用の除麇機稼動時より鹿埃是は
全体にやや多くなった．これは薬蝔の発生は分包時より る調剤時の方が多いことを意味している.

\section{喚煌による暳埃テスト}

表 $1 \sim 4$ から $03 \sim 0.5 \mu$ の小さい粒径の蝔埃は必ずし も啁剂によって多くなるとはいえず，调阂室以外の所の 方が多い場合がしばしばあるが，1. 0 5.0 0 の粒径の大 きい麇埃は調剤により非常に多くなる。これは小さい粒 径のものは人の動きや契煙などによる影響が大きく，と

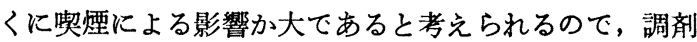
終了後の人のいない调剤室（A点）においてタハコ（セ ブンスター）一本を腎った埸合の麇埃量を則定し，表 7 に示した

表 7 宧煙による麾埃テスト（タハコ1本）

\begin{tabular}{|c|c|c|c|c|c|c|c|c|c|c|}
\hline 杜子佳 & 除しん杪 & 0 & 1 & 2 & 4 & 6 & 8 & 15 & 20 & 30 (分) \\
\hline $0.3 \mu$ & $\begin{array}{l}\text { 有 } \\
\text { 無 }\end{array}$ & $\begin{array}{l}1357 \\
1579\end{array}$ & $\begin{array}{r}6170 \\
11073\end{array}$ & $\begin{array}{l}11247 \\
26962\end{array}$ & $\begin{array}{r}3221 \\
20387\end{array}$ & $\begin{array}{r}1710 \\
18836\end{array}$ & $\begin{array}{r}1248 \\
18051\end{array}$ & $\begin{array}{r}937 \\
14665\end{array}$ & 14222 & 12694 \\
\hline $0.5 \mu$ & $\begin{array}{l}\text { 有 } \\
\text { 無 }\end{array}$ & $\begin{array}{l}70 \\
83\end{array}$ & $\begin{array}{r}491 \\
6144\end{array}$ & $\begin{array}{r}1262 \\
10810\end{array}$ & $\begin{array}{r}185 \\
4394\end{array}$ & $\begin{array}{r}92 \\
3333\end{array}$ & $\begin{array}{r}59 \\
2906\end{array}$ & $\begin{array}{r}46 \\
1883\end{array}$ & 1739 & 1385 \\
\hline $1.0 \mu$ & $\begin{array}{l}\text { 有 } \\
\text { 無 }\end{array}$ & $\begin{array}{l}3 \\
7\end{array}$ & $\begin{array}{r}5 \\
2298\end{array}$ & $\begin{array}{r}25 \\
831\end{array}$ & $\begin{array}{r}7 \\
83\end{array}$ & $\begin{array}{r}5 \\
50\end{array}$ & $\begin{array}{r}3 \\
40\end{array}$ & $\begin{array}{r}5 \\
30\end{array}$ & 33 & 28 \\
\hline $2.0 \mu$ & $\begin{array}{l}\text { A } \\
\text { 無 }\end{array}$ & $\begin{array}{l}0 \\
1\end{array}$ & $\begin{array}{r}1 \\
77\end{array}$ & $\begin{array}{l}6 \\
3\end{array}$ & $\begin{array}{l}2 \\
2\end{array}$ & $\begin{array}{l}0 \\
1\end{array}$ & $\begin{array}{l}2 \\
0\end{array}$ & $\begin{array}{l}1 \\
3\end{array}$ & 4 & 2 \\
\hline $5.0 \mu$ & $\begin{array}{l}\text { 什 } \\
\text { 無 }\end{array}$ & $\begin{array}{l}0 \\
0\end{array}$ & $\begin{array}{l}0 \\
0\end{array}$ & $\begin{array}{l}2 \\
0\end{array}$ & $\begin{array}{l}0 \\
0\end{array}$ & $\begin{array}{l}0 \\
0\end{array}$ & $\begin{array}{l}0 \\
0\end{array}$ & $\begin{array}{l}0 \\
0\end{array}$ & 1 & 0 \\
\hline
\end{tabular}

除鹿嘰の停止時，タバュ一本の契煙により 2 分後には 粒径 $0.3 \mu$ の歴埃は $26962 \times 10^{3}$ 個となり，0 $5 \mu$ は $10810 \times$ $10^{3}$ 個と唤煙前に比へてて 17 130 倍と非常に多くなるが, 2.0 5.0 $\mu$ の粒径の大きい歴埃はほとんど変化なく，喫 煙以前とほとんど差はなかった，そして鄙䃌後30分たっ

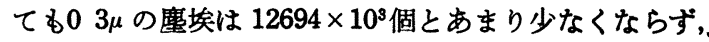

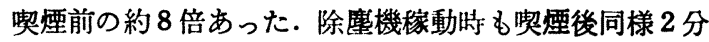
で $11247 \times 10^{3}$ 個と最高になり，整煙前の約 8 倍となっ た. しかし 6〜10分後には喫煙前と囘程度に減少した 粒径の大きい塵埃は除麇機停止時同様变化はなかった。

从上の実験のように薬局調剂室の薬蝔は $10 \sim 50 \mu$ 以 上の粒径の大きいものが調剂, 分包により発生し, 03 亿 $05 \mu$ の粒径の小さい鹿埃は調剤以外の要因によって左右 され，とくに喫煙による影響は大であるこの観はから
も啁片室内の禁煙は有意義てあると考える。

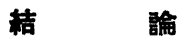

薬局調剂室に拈ける薬蝔対策として薬塵発生源近くに 除塵機を設置し，これによって蝔埃を1/10～1/50 亿減 少することができた。除塵機から離れた場所においては 蝔埃は 1/3 1/15 亿城少するが，除去率は当然低くなっ た 调剂により発生する薬蝔には 1.0 5 $0 \mu$ と粒径の比 較的大きいものか多く，03〜0 5 は孯煙，人の動きなどの調剂以外の要因による影響が大 てあったしたがって調剤室の塵埃は 1.0 5 $0 \mu$ 以上の

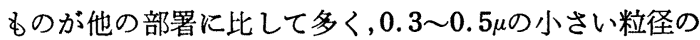
ものは大きな差はなかった 薬麇発生源近くに除塵機を 設置すると調剂により発生した $10 \sim 50 \mu$ 以上の薬蝔を 
除去するので調剤室全体にこの大きさの麇埃数は少なく なり、調郕室内の場所による差は少なくなった。しかし 调剤以外の要因により発生する $0.3 \sim 0.5 \mu$ の小さい㑛战 は除憵機から離れた場所に括いては除去率が低下゙するの

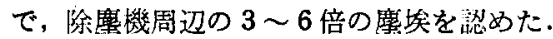

湖辟 本研究にあたり，で指導で校閲いただいた名古 屋大学医学部衛生学教室, 松本忠雄講師、ならびに测定 機器の使用に便宜をはかっていただいた株式会社東京辟 会に梁く感謝いたします。

$$
\text { 交献 }
$$

1）佐竹交介：耳無㸶㞺科，45,843(1973).
2）戸所正雄，神边淁，中村俊，井出かか子：フレル ギー, 21, 288 (1972).

3）中村丝: フレルギー, 21，288 (1972).

4) 本間誠一, 近藤志德, 小林敏男, 笛木隆三, 小林 節雄，互野進乎：フレルギー， 23，198 (1974).

5）藤深德太郎，西止朋，鳥居皇二，小野守生，桑木

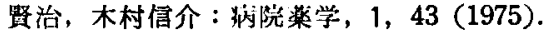

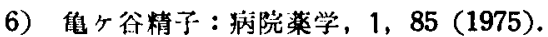

7）后瀨朝炏，岩崎由婎，上野高正，馗藤太郎，永瀬

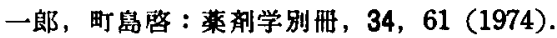

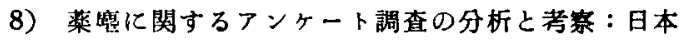
实院薬剂師会, 1979年 8 月.

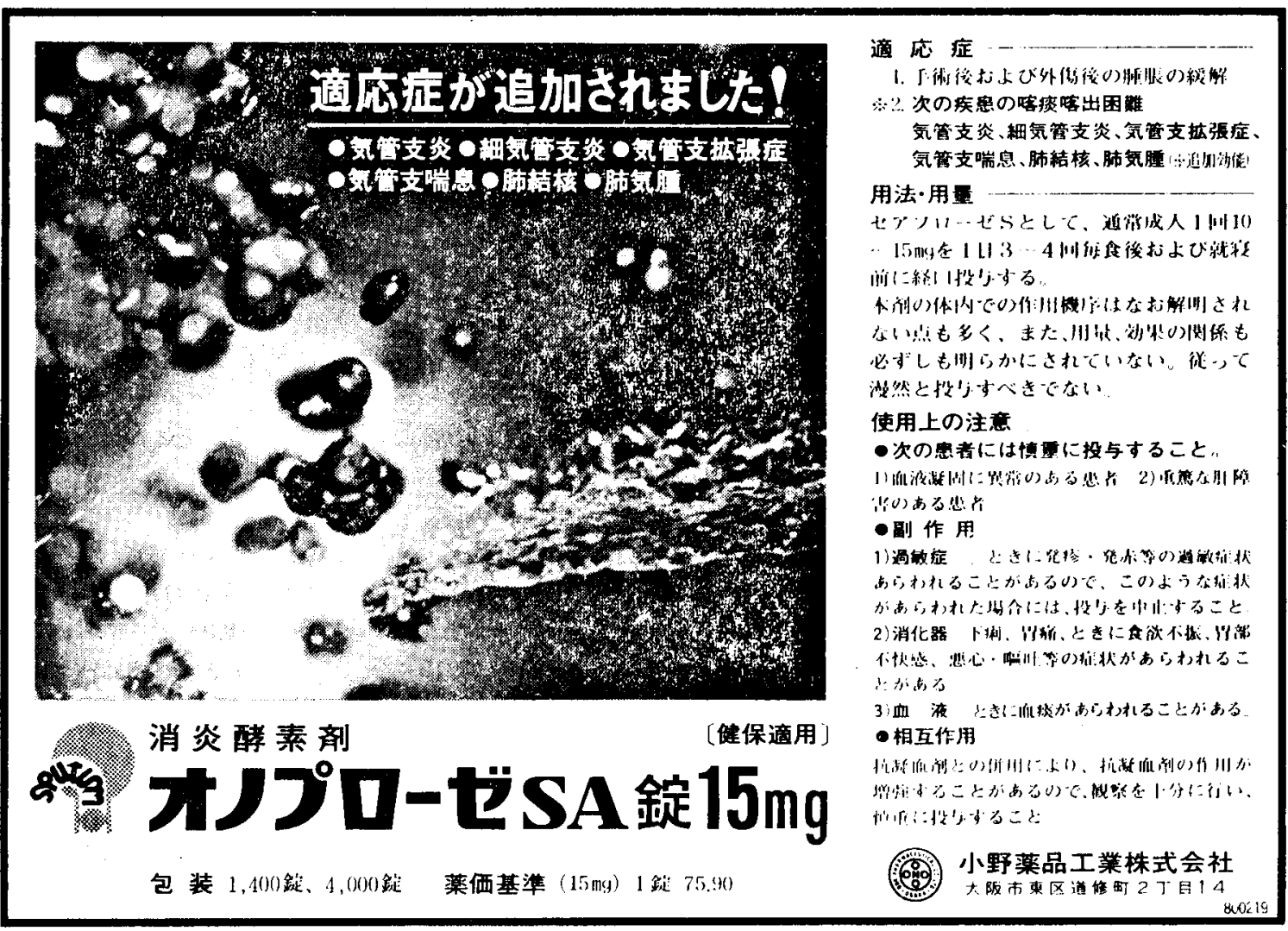

